\title{
Priming Low-Dose Gamma Irradiation Increases Cellular Radioadaptation Response through the Induction of Hsp70 and SOD2
}

\author{
Supriyadi * \\ Dental Radiology Laboratory, Faculty of Dentistry, Jember University, Jember, East Java 68121, Indonesia
}

\section{ARTICLE INFO}

Article history:

Received 23 December 2019

Received in revised form 7 December 2020

Accepted 7 December 2020

Keywords:

Priming dose

Gamma ray radiation

Radioadaptation response

Hsp70

SOD2

\begin{abstract}
A B S T R A C T
Exposure to low-dose radiation has been demonstrated to stimulate increased cell protection when receiving subsequent challenge dose in what is known as radioadaptation response. Hsp70 and SOD, especially SOD2, are cytoprotectors against superoxide radicals generated by radiation exposure. This study aims to measure the expressions of Hsp70 and SOD2 in parotid salivary gland acinar cells as an indicator of radioadaptation response stimulated by low-dose gamma irradiation. The study used 24 male Rattus norvegicus that are divided into four groups: normal control, positive control, with 50-mGy priming irradiation, and with 100 -mGy priming irradiation. The animals were immobilized without anesthetics with special tools designed especially for this study. Irradiation was carried out using a cobalt-60 (gamma ray) teletherapy unit (Philips XK-100) directed to the dorsa of the animals' heads. High-dose gamma irradiation (2 Gy) was administered 5 hours after priming irradiation. The expression of Hsp70 and SOD2 was measured through immunohistochemical technique on the parotid salivary gland acinar cells and observed using a light microscope with $1000 \times$ magnification. Data obtained was analyzed with one-way ANOVA test $(\alpha=0.05)$. The results showed that Hsp70 and SOD2 expressions in the priming irradiation groups were higher than those in control groups. The conclusion of this study: priming irradiation with low-dose gamma radiation before challenge irradiation with high-dose gamma radiation increases the radioadaptation response of salivary gland acinar cells through induction of Hsp70 and SOD2.
\end{abstract}

(C) 2021 Atom Indonesia. All rights reserved

\section{INTRODUCTION}

In the last few decades, low-dose radiation (LDR) has been the focus of radiation research because of the discovery of the health benefits of low-dose radiation known as the phenomenon of radioadaptation response, or adaptation response toward radiation. Adaptation response is one of the defense systems possessed by living organisms, including humans, to fight various genotoxic agents or minimize damage to cell or tissue due to them. Radioadaptation response can be demonstrated by the ability of a biological system exposed to a small priming stress to exhibit a lower detrimental effect on subsequent reception of another, higher radiation

\footnotetext{
*Corresponding author.

E-mail address: supriyadi.fkg@unej.ac.id

DOI: https://doi.org/10.17146/aij.2021.1019
}

dose, known as the challenge dose [1]. An LDR is a radiation with a dose below $200 \mathrm{mGy}$ [2].

There have been many studies, both in vitro and in vivo, that have proven this phenomenon of radioadaptation response. The studies continue to determine the radiation dose ranges that can be considered as low doses, the source of radiation, the cell or tissue for the target of radiation, and the indicators of the occurrence of radioadaptation response.

Radioadaptation response refers to beneficial effects of stressors that induce a response that results in stress resistance [3]. The main mechanism of the cellular defense systems to explain the radioadaptation response at the molecular level is through the enhancement of antioxidant system such as superoxide dismutase (SOD) and induction of protein synthesis through 
induction stress proteins such as the 70 kilodalton heat shock protein (Hsp70) family [4]. Heat shock response (HSR) plays an important role in producing hormetic effects or adaptation response. HSR is a coordinated induction of specific molecular chaperones (heat shock proteins, HSPs) in response to different cellular stresses, can also play an important role in yielding hormetic effects [5]. Hsp70 is a protein that has an important role in protein folding or preventing protein misfolding due to heat and other stresses including oxidative stress due to accumulation of reactive oxygen species (ROS) [6]. Meanwhile, SOD, especially SOD2, is the first line of antioxidant enzymatic defenses that play an important role in preventing the accumulation of ROS [7]. SOD is the most common enzymatic antioxidant which converts superoxide into hydrogen peroxide $\left(\mathrm{H}_{2} \mathrm{O}_{2}\right)$ in mitochondria and cytosol [3], so that the formation of ${ }^{\circ} \mathrm{OH}$ radicals can be prevented. Superoxide anions are the ROS most commonly formed after radiation exposure.

Other bioindicators for radioadaptation response are activation of DNA damage repair system, induction of apoptosis, cell cycle regulation, and enhancement of the immune system including both innate immune response (e.g., NK cells and macrophages) and adaptive immunity (e.g., T-cell and B-cell) [1,2,8]. LDR may enhance the activity of NK cells by stimulating cell proliferation and promoting the cytotoxic function of NK cells [8]. Molecular mechanism of adaptation response to low-dose ionizing irradiation has been related to the repair of DNA double-strand breaks (DSBs) and p53 protein plays a key role in the adaptation response [9]. Other antioxidants have been reported in relation to radioadaptation responses such as catalase (CAT), glutathione peroxidase (GPX), glutathione S-transferase (GST), reduced form of glutathione (GSH), and thioredoxin (TRX) $[10,11]$. In our previous study, it was found that exposure to low-dose radiation in the form of $\mathrm{X}$-ray from skull radiography resulted in increased expression of Hsp70 and SOD2 and MDA metabolites of parotid gland acinar cells after exposure to high-dose gamma radiation [12].

Gamma rays have been widely used in medicine, especially in radiotherapy. The purpose of this study is to measure the expressions of Hsp70 and SOD2 in parotid salivary gland acinar cells as an indicator of radioadaptation response stimulated by low-dose gamma irradiation. In this research, the Hsp70 and SOD2 expressions are measured using the immunohistochemistry (IHC) technique. Immunohistochemistry is a laboratory examination to determine the location of cell proteins in tissue sections. IHC is based on the binding of specific antibodies to antigens in biological tissues. These antibody-antigen bonds can be seen by conjugating these antibodies with enzymes (e.g., peroxidase) that can catalyze reactions that produce color. Immunohistochemistry is quite representative for examining the expression of certain proteins. In clinical practice, IHC can improve the accuracy of histological assessment [13].

\section{EXPERIMENTAL METHODS}

\section{Research design}

Ethical clearance for this study was obtained from the Ethics Commission of Research and Development Department, Dr. Sutomo Hospital, Surabaya, East Java, Indonesia, with document number 28/Panke.KKE/I/2017. This experimental study used randomized post-test only control group design. Twenty-four Rattus norvegicus were used and randomly assigned into four groups as follows: Group 1: normal control; Group 2: samples were only exposed to high-dose gamma radiation (2 Gy); Group 3: samples were exposed to low-dose gamma radiation $(50 \mathrm{mGy})$ followed 5 hours later with exposure to high-dose gamma radiation; and Group 4: samples were exposed to low-dose gamma radiation (100 mGy) and 5 hours later were exposed to high-dose gamma radiation. The animals that had been selected were adapted in their cages until the research was conducted.

\section{Animals preparation}

The animals were immobilized without anesthetics with a special tool designed especially for this study (tapered form bottles from plastic materials given ventilation holes along the surface). The animals which had been put in the bottle were then fixed on a board.

\section{Irradiation procedure}

Exposure to low-dose gamma radiation (50 mGy, $100 \mathrm{mGy}$ ) and high-dose gamma radiation (2 Gy) using a Cobalt-60 teletherapy unit (Philips type XK-100) with a sources-surface distance (SSD) of $80 \mathrm{~cm}$, and a wide area of radiation $20 \times 20 \mathrm{~cm}^{2}$. Irradiation was directed to the dorsal part of the animal's head. In the animal control group, immobilization was carried out with the same technique and duration. 


\section{Immunohistochemical (IHC) analysis}

Twenty-four hours after the irradiation, parotid tissue was removed immediately and then stored in a fixation solution (formalin buffer $10 \%$ ). Afterward, the parotid tissue was processed to produce histopathology specimens and then stained with IHC techniques as described previously. Briefly, the specimens were introduced into xylol twice, each for 2 minutes, and then immersed in alcohol of a series of concentrations $(100 \%, 95 \%, 80 \%$, and $70 \%)$ every 1 minute. Then, they were washed with running water (10-15 minutes) and then put into in a $3 \% \quad \mathrm{H}_{2} \mathrm{O}_{2}$ solution for 30 minutes. Subsequently, they were washed with phosphate buffered saline (PBS) solution three times, each for 2 minutes, dripped with trypsin $0.025 \%$ and incubated for 6 minutes at $37^{\circ} \mathrm{C}$, washed with PBS three times for 2 minutes each. Then, specimens were incorporated with enzyme-labeled monoclonal antibodies (anti-mouse anti-Hsp70 antibody, antimouse anti-SOD2 antibody) and incubated for 30 minutes at $37^{\circ} \mathrm{C}$, washed with PBS three times each 2 minutes. After that, they were dripped with horseradish peroxidase (HRP) for 30 minutes, washed with PBS three times each 2 minutes. Finally, they were washed into chromogen subtract for 5 minutes, washed with PBS three times each 2 minutes, washed with aqua distillata, put in Mayer's Haematoxylin for six minutes, washed with running water until they were clean, and then dehydrated, cleared, and mounted [12].

\section{Data colection and statistical analysis}

The measurement of Hsp70 and SOD2 expression was carried-out under a 1000x magnification microscope in 20 fields of view, and then their mean was taken. The data was analyzed using one-way ANOVA test to compare between all groups. All data analysis used $\alpha=0.05$; thus, the values of $p \leq 0.05$ were considered statistically significant.

\section{RESULTS AND DISCUSSION}

\section{Hsp70}

The Hsp70 expression of parotid salivary gland acinar cells is shown in Fig. 1, while the data on Hsp70 expression and the results of statistical test is presented in Table 1.

Table 1 shows that the groups expossed to LDR exhibit a higher expression of Hsp70 than the two control groups. The highest Hsp70 expression is shown by Group 3 (50 mGy priming irradiation), while the lowest Hsp70 expression occurs in Group 1 (normal control). The results of statistical analysis with one-way ANOVA test obtained $p=0.000(p<\alpha)$, meaning that there is a significant difference between the four groups. LSD (least-significant difference) test indicates that there are significant differences between Group 1 and Group 3, between Group 1 and Group 4, and between Group 3 and Group 4. Meanwhile, between Group 1 and Group 2 there are no significant differences.
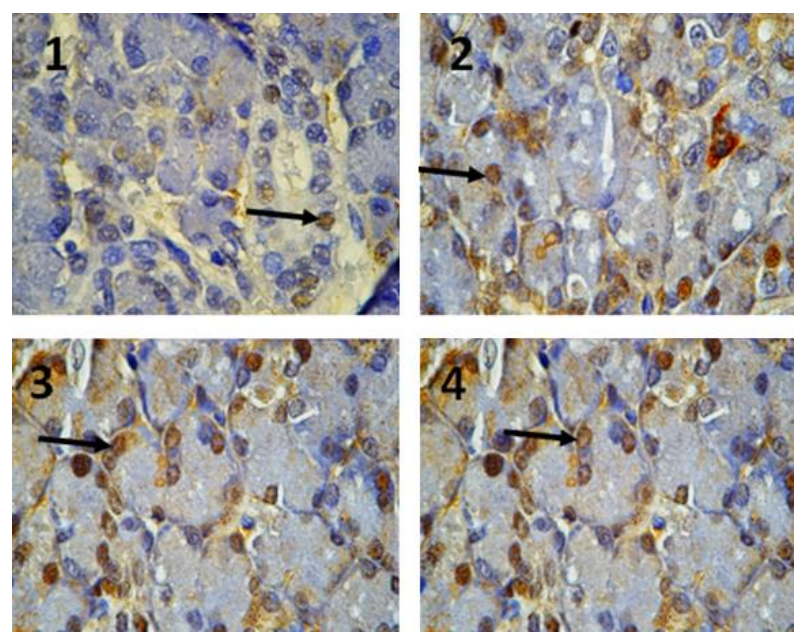

Fig. 1. Immunohistochemical micrographs of the parotid salivary gland cells that express Hsp70 (arrow, showing cells expressing Hsp70).

Table 1. Hsp70 expression of parotid salivary glands acinar cells in all groups.

\begin{tabular}{|c|c|c|c|c|c|}
\hline \multirow{2}{*}{ Group } & \multicolumn{4}{|c|}{ Hsp70 } & \multirow{2}{*}{$\begin{array}{c}\text { One-Way } \\
\text { ANOVA } \\
\text { (p) }\end{array}$} \\
\hline & Mean & $\begin{array}{l}\text { Standard } \\
\text { Deviation }\end{array}$ & Min & Max & \\
\hline 1 & $4.83^{\mathrm{a}}$ & 1.941 & 3 & 8 & \multirow{4}{*}{0.000} \\
\hline 2 & $7.33^{\mathrm{a}}$ & 2.160 & 4 & 10 & \\
\hline 3 & $15.33^{\mathrm{c}}$ & 2.251 & 13 & 19 & \\
\hline 4 & $12.17^{b}$ & 1.722 & 10 & 14 & \\
\hline
\end{tabular}

Note:

${ }^{\mathrm{abc}}$ superscript $=$ LSD test (superscript: same shows no

$1=$ normal control significant differences)

$2=$ positive control

$3=$ with 50-mGy priming irradiation

4 = with 100-mGy priming irradiation

\section{SOD2}

The SOD2 expression of parotid salivary
gland acinar cells is shown in 
Fig. 2 while the data on Hsp70 expression and the results of statistical test is presented in Table 2.
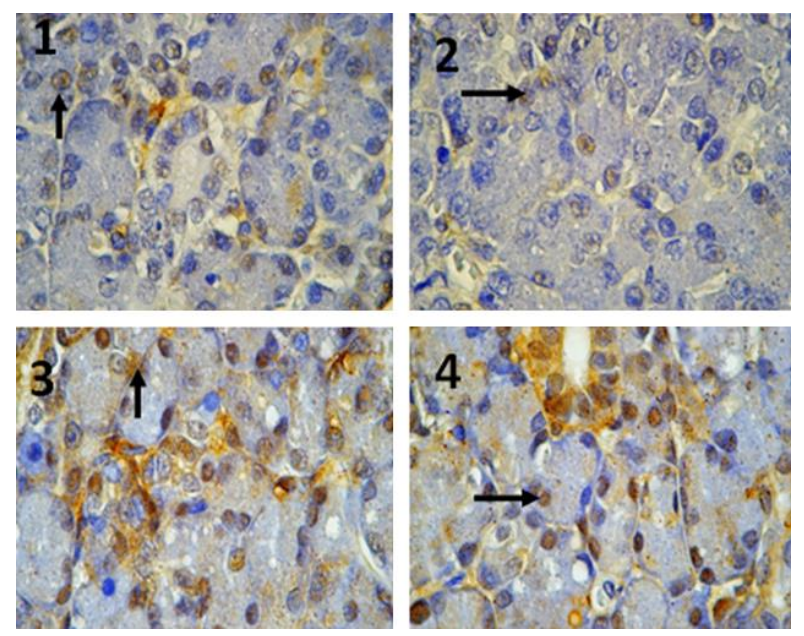

Fig. 2. Immunohistochemical micrographs of the parotid salivary gland cells that express SOD2 (arrow, showing cells expressing SOD2).

Table 2. SOD2 expression of parotid salivary glands acinar cells in all groups.

\begin{tabular}{|c|c|c|c|c|c|}
\hline \multirow[b]{2}{*}{ Group } & \multicolumn{4}{|c|}{ SOD2 } & \multirow{2}{*}{$\begin{array}{c}\text { One-Way } \\
\text { ANOVA } \\
(\mathbf{p})\end{array}$} \\
\hline & Mean & $\begin{array}{l}\text { Standard } \\
\text { Deviation }\end{array}$ & Min & Max & \\
\hline 1 & $7.00^{\mathrm{a}}$ & 2.280 & 5 & 11 & \multirow{4}{*}{0.000} \\
\hline 2 & $6.33^{\mathrm{a}}$ & 2.503 & 3 & 9 & \\
\hline 3 & $10.33^{b}$ & 1.211 & 9 & 12 & \\
\hline 4 & $10.67^{b}$ & 1.506 & 9 & 13 & \\
\hline
\end{tabular}

\footnotetext{
Note:

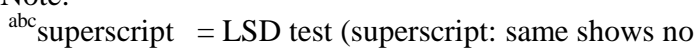

$1=$ normal control significant differences)

$2=$ positive control

$3=$ with $50-\mathrm{mGy}$ priming irradiation

$4=$ with $50-m G y$ priming irradiation
}

Table 2 shows that the groups exposed to LDR display a higher expression of SOD2 than the two control groups. The highest SOD2 expression is shown by Group 4 (priming irradiation $100 \mathrm{mGy}$ ) while the lowest SOD2 expression is available in Group 2 (positive control). The results of statistical analysis with one-way ANOVA test obtained $p=0.000(p<\alpha)$, meaning there is a significant difference between the four groups. LSD test indicates a significant difference between Group 1 and Group 3 and between Group 1 and group 4. However, there are no differences between Group 1 and Group 2 and between Group 3 and Group 4.
There is no doubt about the damaging effects of high-dose radiation (HDR) exposure to molecules, cells, or organisms. However, the debate lies among proponents of the linearity with threshold concepts (threshold model) versus linear no-threshold concepts (LNT) but not with a LDR. Cellular response to LDR does not always follow the LNT hypothesis. Biological effects of LDR at certain dose levels are different from those of HDR $[2,14]$. The LNT hypothesis postulates that the effects of radiation can occur without having a threshold. It assumes that any dose, no matter how low, can initiate cell and tissue damage, especially by induction of mutation and cancer risk $[15,16]$. In this study, the radioadaptation response was evaluated on the acinar cells of the parotid salivary glands. Its results provided evidence that LDR exposure before HDR exposure was able to stimulate a favorable radioadaptation response, such as increased Hsp70 as a cell protector and endogenous antioxidants SOD2.

The results of this study are consistent with the results of our previous studies, which used $\mathrm{X}$-rays from a skull radiography device as the LDR to induce a radioadaptation response [12]. Exposure doses of X-ray in head or skull radiography ranges from 3.01 to $19.12 \mathrm{mGy}$ with a mean of $7.52 \mathrm{mGy}$ [17], while this study used low-dose gamma rays of $50 \mathrm{mGy}$ and $100 \mathrm{mGy}$. The increased priming irradiation doses up to $50 \mathrm{mGy}$ and $100 \mathrm{mGy}$ to induce radioadaptation response factually gives the similar results with dose of priming irradiation on skull radiography. Induction of low-dose gamma irradiation with dose of $50 \mathrm{mGy}$ and $100 \mathrm{mGy}$ in this study also resulted in increased expression of Hsp70 and SOD2. The results of this study certainly support several previous researchers' statement that the LDR which can initiate a radioadaptation response has a dose range of 1-100 mGy or below 200 mGy $[1,2]$.

The Hsp70 is a stress response protein. Exposure to ionizing radiation will cause the cell to experience oxidative stress. Oxidative stress condition will cause a variety of disorders in cells including disorders of protein and lipid function [18]. Protein disorders will be responded to by inducing the increased Hsp70 through the induction of HSF-1 transcription factors. The induced HSF-1 will then activate enzymes that are bound to the heat shock element (HSE) in the nucleus and will eventually induce the HSP gene to increase transcription, synthesis, and functionalization of Hsp especially Hsp70 [1,19]. This study shows that there is an increase in Hsp70 expression both in the group given priming 
irradiation and in the group without priming irradiation. Nevertheless, in the group given priming irradiation, the expression of the increased $\mathrm{Hsp} 70$ is higher.

The increased SOD2 expression in this study is consistent with several previous studies. Miura in his article suggests that after exposure to radiation challenges, endogenous antioxidants (superoxide dismutase, catalase, and glutathione) have a higher activity in the group exposed to priming irradiation compared to without priming irradiation [20]. Several other researchers suggest that antioxidant defense plays a role in adaptation responses. Yang et al. in their article mention that LDR-induced hormesis could also stimulate a system of protective biological processes, thereby subsequently alleviating tissue damage. LDR has been reported to increase the levels of various type of antioxidants both in vitro and in vivo [2]. Likewise, Jin et al. in their research argue that the induction of radioadaptation response is mediated by MnSOD. They found that after a challenge radiation dose of $5 \mathrm{~Gy}$, MnSOD activity increases in the group exposed to $10 \mathrm{cGy}$ priming radiation [21]. Different results were obtained in the study by Abdelrazek et al. They found that a priming dose of $10 \mathrm{cGy}$ given $24 \mathrm{~h}$ prior to a challenge dose of $2 \mathrm{~Gy}$ did not protect the liver of the irradiated rats against DNA damage, lipid peroxidation, or protein oxidation for the time point used (24 h) [14].

SOD is the primary and the first level antioxidant in the body due to its ability to protect cells from free radicals. SOD is a major intracellular antioxidant. SOD2 (Mn-SOD) is one of the important cytoprotectors. MnSOD is essential for the survival of all aerobic organisms, and it contributes to the development of cellular resistance to ROS (oxidative stress condition) [7]. SOD2 catalyzes the dismutation of superoxide radicals into hydrogen peroxide and oxygen. Superoxide radicals are radicals that are mostly formed after exposure to radiation. The increased SOD2 expression induced by priming irradiation plays a role in inhibiting the formation of ROS due to subsequent radiation with higher doses. SOD (especially Mn-SOD2) is found in various cell types. SOD is regulated by the MnSOD gene through activation of the nuclear factor erythroid 2-related factor 2 (Nrf2) transcription factor $[1,22]$. The presence of SOD2 is important since damage to DNA and other molecules due to radiation are mostly caused by free radicals or indirect effects. This is because about $75 \%$ of the mass of cells or tissues consists of water [12,23].
Priming irradiation was administered 5 hours before exposure to challenge irradiation. In this timespan, the cell was in an adapted state. If cells are exposed to higher doses of radiation in this timespan, the cells will respond more quickly by inducing the transcription factors HSF-1 to increase transcription and synthesis of $\mathrm{Hsp}$ (inducible-Hsp) and also by inducing the transcription factors Nrf2 to increase antioxidant (SOD2) activity. The interval time between priming irradiation and challenge irradiation is the time of gene activation, and at this time interval, cells are more resistant to challenge irradiation [1]. Previous in-vitro and in-vivo studies have reported that low-dose irradiation (250-500 mGy) can detoxify the damaging effects of ROS formation by increasing the production of antioxidants (glutathione and superoxide dismutase) 3-6 hours post-irradiation [24]. The radioadaptation response that has been studied has an optimal dose range of below $0.1 \mathrm{~Gy}$ and is maximally expressed at 4-6 hours after irradiation and continues for more than 20 hours [9]. One study also reported that mRNA expression for $\gamma$-glutamylcysteine synthetase $(\gamma$-GCS $)$ increased immediately after low-dose gamma irradiation $(0.5 \mathrm{~Gy})$, and peaked between 3 hours and 6 hours after irradiation. It is known that $\gamma$-GCS is an enzyme involved in the biosynthesis of GSH from its constituent amino acids [10].

\section{CONCLUSION}

Priming irradiation with low-dose gamma radiation before challenge irradiation with high-dose gamma radiation increases the radioadaptation response of salivary gland acinar cells through induction of Hsp70 and SOD2.

\section{ACKNOWLEDGMENT}

The author would like to thank the Ministry of Research and Higher Education, Indonesia, for funding this research.

\section{AUTHOR CONTRIBUTION}

I, the author, herewith declare that I have no conflicts of interest in the writing of this manuscript. I am the sole contributor to this manuscript and have approved its final version. 


\section{REFERENCES}

1. Y. Guéguen, A. Bontemps and T. G. Ebrahimian, Cell. Mol. Life Sci. 76 (2019) 1255.

2. G. Yang, W. Li, H. Jiang et al., Int. J. Cancer 139 (2016) 2157.

3. J. G. Steller, J. R. Alberts and A. E. Ronca, Int. J. Mol. Sci. 19 (2018) 3729.

4. Y. Shibamoto and H. Nakamura, Int. J. Mol. Sci. 19 (2018) 2387.

5. A.Vaiserman, A. Koliada and Y. Socol, The Science of Hormesis in Health and Longevity, Academic Press, London (2019) 129.

6. Y. H. Park, J. H. Seo, J. H. Park et al., Int. J. Oncol. 51 (2017) 573.

7. Azhari, S. Sitam, S. Darana et al., J. US-China Med. Sci. 13 (2016) 154.

8. J. Cui, G. Yang, Z. Pan et al., Int. J. Mol. Sci. 18 (2017) 1.

9. Z. Alatas, Atom Indonesia 41 (2015) 61.

10. Y. Kawakita, M. Ikekita, R. Kurozumi et al., Biol. Pharm. Bull. 26 (2003) 19.

11. N. Paraswani, M. Thoh, H. N. Bhilwade et al., Mutat. Res. Gen. Tox. En. 831 (2018) 50.

12. Supriyadi, T. K. S. Prija and R. P. Rahayu, J. Int. Dent. Med. Res. 11 (2018) 804.

13. T. Nagao, E. Sato, R. Inoue et al., Acta Histochem. Cytochem. 45 (2012) 269.
14. A. B. Abdelrazzak, M. A. El-Missiry, M. T. Ahmed et al., Int. J. Radiat. Biol. 95 (2019) 264.

15. J. Klapacz and B. B. Gollapudi, Environ. Mol. Mutagen. 61 (2020) 84.

16. J. A. Lemon, N. Phan and D. R. Boreham, Radiat. Res. 188 (2017) 495.

17. J. A. Achuka, M. Aweda and M. R.Usikalu, IOP Conf. Ser.: Earth Environ. Sci. 173 (2018) 12038.

18. I. V. Guzhova and B. A. Margulis, Hum. Vaccines \& Immunotherapeutics 12 (2016) 2529.

19. S. S. Kim, J. H. So and J. S. Park, J. Life Sci. 26 (2016) 1360.

20. Y. Miura, J. Radiat. Res. 45 (2004) 357.

21. C. Jin, L. Qin, Y. Shi et al., Free Radical Biol. Med. 81 (2015) 77.

22. K. R. Sekhar and M. L. Freeman, Free Radical Biol. Med. 88 (2015) 268.

23. H. N. E. Surniyantoro, T. Rahardjo, T. Lusiyanti et al., Atom Indonesia 45 (2019) 123.

24. S. N. Pramojanee, W. Pratchayasakul, N. Chattipakorn et al., Arch. Oral Biol. 57 (2012) 252. 